\title{
Autonomic Function Tests in a Patient with Postural Orthostatic Tachycardia Syndrome after Varicella Zoster Virus Infection
}

\author{
Pranith Kumar ${ }^{1 *}$, Supriya Gupta ${ }^{1}$, Raj Kapoor ${ }^{1}$, Raghavan $S^{2}$ and Bhavna Kaul ${ }^{2}$ \\ ${ }^{1}$ Department of Physiology, V.M.M.C and Safdarjung Hospital, India \\ ${ }^{2}$ Department of Neurology, V.M.M.C and Safdarjung Hospital, India
}

Submission: November 23, 2016; Published: January 23, 2017

*Corresponding author: Pranith Kumar, Department of Physiology, V.M.M.C and Safdarjung Hospital, New Delhi, India, Email: pranith.kumar7@gmail.com

\section{Case Presentation}

A 26 year old male was referred to our hospital because of 2 episodes of syncope. The first episode was associated with a loss of consciousness for 2 minutes, which occurred during micturition. The second episode occurred within 2 weeks of the first episode. There was no history of seizure like activity during the episodes. There was history of difficulty concentrating in studies, lightheadedness on getting up from bed, mental clouding and confusion for several months prior to the syncopal episode. There was history of tremulousness in his legs. Thereafter he started experiencing severe fatigue. History of palpitations was also present. Patient had a past history of Varicella Zoster infection just prior to his prodromal symptoms, for which he was admitted and also received anti- viral therapy infection had resolved.

Patient was referred to our hospital for evaluation of his syncope. An E.C.G. showed no abnormalities. 24 hour holter monitoring was normal. An ECHO was also performed and showed no abnormalities. Laboratory values were within normal range including blood sugar, C.B.C, ESR, liver function, renal function and thyroid. Chest $\mathrm{x}$ ray was normal. EEG was normal. Adrenal insufficiency was excluded. Pulmonary function tests were normal (FVC - 92\%, FEV1 -93\%, FEV1/FVC - 103\%). He was then referred to our autonomic lab.

\section{Head up tilt test}

We suspected an orthostatic intolerance. A head up tilt test was performed in a quiet room with controlled temperature and the patient was in a fasting state. E.C.G was recorded continuously using BIOPAC MP150 instrument and Acqnowledge version 4.2 software. Blood pressure was continuously monitored by non invasive blood pressure amplifier (Finapres NIBP 100D by Biopac). After resting for 15 minutes in supine position a tilt up to 70 degrees was performed on a tilt table with a foot board for 30 minutes. His resting heart rate was $83 \mathrm{bpm}$ and blood pressure was $125 / 70 \mathrm{~mm}$ $\mathrm{Hg}$. After seven minutes of tilt there was an abrupt increase in heart rate from 83 beats per minute to 134 beats per minute without any rise or fall in blood pressure. The patient started complaining of lightheadedness but he did not experience syncope. As he was returned to supine position a few minutes later his heart rate went back towards normal swiftly. POTS was diagnosed and he was started on fludrocortisone tablets. Elastic support device for the legs were prescribed. He was also given instructions for an aerobic exercise regimen. He was also told to adequately supplement water and salt in his diet. His symptoms resolved within 6 weeks.

\section{Discussion}

Postural Orthostatic tachycardia syndrome (POTS) is one of the most common manifestations of chronic orthostatic intolerance. POTS typically affects people of the age group 15 to 50 years. The current criterion for diagnosing POTS is an increase in heart rate of 30 beats/min or more within 10 minutes of standing or head up tilt test in the absence of orthostatic hypotension, the heart rate usually being 120 beats/min or higher [1]. Whereas for individuals of the age group 12-19 yrs, an increase in heart rate of 40 beats/ min is required [2]. There are symptoms of associated sympathetic hyperactivity and cerebral hypoperfusion. The symptoms include light headedness, blurred vision, cognitive difficulties, generalized weakness, palpitations, chest pain and tremulousness.

The symptoms are mostly related to standing and relieved by lying down. Typical symptoms include light headedness weakness, dizziness, breathing difficulties, tremulousness, palpitations, vision changes, pre syncopal symptoms, anxiety and less commonly syncope. The cardinal clinical sign in POTS is the presence of an abnormal tachycardia on the assumption of upright posture. Rarer physical signs include the development of acrocyanosis in $40-50 \%$ of the cases during prolonged standing. 
The etiology is heterogeneous and the pathophysiology of POTS is not understood definitely. However, many different types have been identified. The 3 main types are neuropathic, hyper adrenergic and POTS related to deconditioning [3]. In the neuropathic form there is a partial sympathetic denervation in the vasculature of the lower limb so that there is an inability of the vessels to constrict in response to orthostatic stress [4]. The hyper adrenergic variant is characterized by an increased nor adrenaline level above $600 \mathrm{pg} /$ $\mathrm{ml}$ and a higher blood pressure on standing [5]. POTS related to deconditioning occurs after a severe illness which leads to bed rest or restricted physical activity. Infection, surgery and trauma are frequent precipitating events [3]. The causes can be classified into primary where the cause is unknown and POTS secondary to another medical condition, commonly diabetes and chronic fatigue syndrome. The other conditions associated with POTS are amyloidosis, sarcoidosis, alcoholism, S.L.E, Sjogren's syndrome, heavy metal intoxication, joint hyper mobility syndrome, pure autonomic failure, M.S.A and paraneoplastic syndromes [4].

\section{Autonomic tests in POTS}

Tests of autonomic nervous system function typically show intact or exaggerated reflex responses though these patients often have preserved vagal function as measured by expiratory: inspiratory (E: I) ratio [6]. Our patient had a normal deep breathing test and valsalva ratio. However, he had an exaggerated response to the cold pressor test and isometric handgrip test.

Our patient presented with several risk factors for POTS. First prolonged bed rest after tuberculosis may have been an initiating event for his physical deconditioning. Second the antitubercular drugs prescribed, particularly isoniazid, is known to cause peripheral neuropathy may also have contributed to the condition. However his condition did not improve after the anti tubercular drugs were discontinued but did improve with a short term regimen and high salt diet. He also did not have any other symptoms of peripheral neuropathy.

Moreover our patient's symptoms were chronologically related to an episode of varicella. Hongliang Li et al. described in their study, an autoimmune basis for POTS [7]. The authors were able to demonstrate auto antibodies in patients with POTS. They described a beta receptor auto antibody as the cause for tachycardia. This observation was supported by the fact that beta blockers are known to improve symptoms of POTS. Molecular mimicry by auto antibodies produced against varicella zoster virus is a possible cause of POTS in our patient.
The Zoster virus is known to establish itself along the sympathetic ganglion.

Alternatively, the patient's symptoms could also be due to a direct affect of the virus in the thoracic paravertebral sympathetic ganglion. Quantitative PCR studies have isolated Varicella Zoster DNA not only from cranial nerve root and dorsal root ganglia but also from thoracic sympathetic ganglion (TSG) [8].

\section{Conclusion}

The report is the first to the best of our knowledge to document occurrence of POTS after a varicella zoster viral illness. We also suggest POTS could be related to anti tubercular drugs which cannot be entirely ruled out. Based on available literature we may be able to determine pathophysiologically as to the cause for the symptoms, but whether causal relationship exists has to be evaluated further.

\section{Consent}

The institutional ethics committee of the medical faculty approved the study and the subject provided written informed consent.

\section{References}

1. Schondorf R, Low PA (1993) Idiopathic postural orthostatic tachycardia syndrome: an attenuated form of acute pandysautonomia? Neurology 43(1): 132-137.

2. Freeman R, Wieling W, Axelrod FB, Benditt DG, Benarroch E, et al. (2011) Consensus statement on the definition of orthostatic hypotension, neutrally mediated syncope and the postural tachycardia syndrome. Clin Auton Res 21(2): 69-72.

3. Low PA, Sandroni P, Joyner M, Shen WK (2009) Postural Tachycardia Syndrome (POTS). J Cardiovasc Electrophysiol 20(3): 352-358.

4. Jacob G, Costa F, Shannon JR, Robertson RM, Wathen M (2000) The neuropathic postural tachycardia syndrome. $\mathrm{N}$ Engl J Med 343(14):1008-1014

5. Grubb BP, Kanjwal Y, Kosinski DJ (2006) The postural tachycardia syndrome: a concise guide to diagnosis and management. J Cardiovascular Electrophysiol 17(1): 108-112.

6. Shibao C, Arzubiaga C, Roberts LJ, Raj S, Black B, et al. (2005) Hyperadrenergic postural tachycardia syndrome in mast cell activation disorders. Hypertension 45(3): 385-390.

7. Hongliang Li, Xichun Yu, Campbell Liles, Muneer Khan, Megan Vanderlinde-Wood, et al. (2014) Autoimmune Basis for Postural Tachycardia Syndrome. J Am Heart Assoc 3(1): e000755.

8. Maria A Nagel, April Rempel, Jonathon Huntington, Forrest Kim, Alexander Choe, et al. (2014) Frequency and abundance of alphaherpesvirus DNA in human thoracic sympathetic ganglia. J Virol 88(14): 8189-8192. 
(C) (1) This work is licensed under Creative (c) Commons Attribution 4.0 Licens

\section{Your next submission with Juniper Publishers} will reach you the below assets

- Quality Editorial service

- Swift Peer Review

- Reprints availability

- E-prints Service

- Manuscript Podcast for convenient understanding

- Global attainment for your research

- Manuscript accessibility in different formats ( Pdf, E-pub, Full Text, Audio)

- Unceasing customer service

Track the below URL for one-step submission https://juniperpublishers.com/online-submission.php 